\title{
Bisphenol A degradation by Fenton Advanced Oxidation Process and operation parameters optimization
}

\author{
Mingming $\mathrm{W}_{\text {ang }}{ }^{1}$, Xiaoli $\mathrm{Su}^{1}$, Songwen $\mathrm{Y}_{\text {ang }}{ }^{1}$, Ling $\mathrm{Li}^{1}$, Chaolin $\mathrm{Li}^{1}$, Feiyun Sun ${ }^{{ }^{*}}$, \\ Jiaju Dong ${ }^{2}$, Yiping Rong ${ }^{2}$ \\ 1 Harbin Institute of Technology, Shenzhen, 518055, China \\ 2 Shenzhen New Land Tool Planning\& A rchitectural Desing Co.lid, Shenzhen, 518172, China
}

\begin{abstract}
Bisphenol A (BPA) is a kind of environmental endocrine disrupting substance, which has been used as an organic chemical as unsaturated polyester resin. The degradation of BPA includes biological methods, physical adsorption and chemical oxidation, all which have their own disadvantages. Owing to its strong oxidization capability and stable treatment performance, Fenton process can degrade organic substances at a high reactive rate and stably effective. In this paper, Fenton oxidation method was optimized to remove BPA in water, during which the intermediate products were analysed to examine its degradation path. The optimal conditions of degradation of B PA by Fenton method were a ratio of $\mathrm{C}\left(\mathrm{H}_{2} \mathrm{O}_{2}\right) / \mathrm{C}\left(\mathrm{Fe}^{2+}\right)$ of 10 , a pH of 3.5, and the degradation rate increased with the increasing of reaction temperature. It was found that Fenton could break the chemical bond at the junction of BPA and isopropyl group to produce $p$-diphenol, phenol, isopropyl phenol and other intermediate products.
\end{abstract}

Keywords: Bisphenol A, Fenton advanced oxidation process, Operation parameters optimization, Intermediates

\section{Introduction}

Bisphenol A (BPA) is a synthetic chemical that does not exist in nature. As an important industrial chemical such as epoxy resin, it brings convenience to human life [1]. Although BPA is a low toxic chemical, it is an environmental endocrine disruptor of additive type, which has been proved to be xenoestrogen by animal experiments. BPA has serious impact on biological reproduction and immune system [2], which is frequently detected in raw water and drinking water [3-4]. Nowadays, with rapid development of electronic manufacture, a large amount of wastewater containing BPA, which could be characterized as wide range, low concentration, high biological toxicity, and difficult degradation under natural conditions, discharge into the water body, to bring potential

${ }^{*}$ Corresponding author: sun_fy@ hit.edu.cn 
threat to ecological environment and human health. Many countries prohibit the use of bottles containing B PA [5-6]. China also forbids the disordered use of BPA, and a lot of related research has been carried out [7]. In 2006, Chinse regualation, Standards for drinking water quality stipulates that the upper limit of BPA emission is $10 \mu \mathrm{g} / \mathrm{L}$.

$M$ any technologies were applied to remove BPA. However, these methods have different defects. For instance, physical adsorption has a disadvantage of equipment manufacturing, microbial degradation may cause secondary pollution [8], oxidation method has a high cost of processing [9]. These defects limit the their real application to a certain extent, therefore, it is urgent to develop a cost-effective technology for B PA treatment [10].

Fenton is an advanced oxidation process (AOP) combined divalent iron salt and hydrogen peroxide [11], and from the late 1960s, Fenton reagent began to be used as oxidant to degrade high concentration organic wastewater [12]. Fenton reagent has been widely used in remediation of organic contaminated soil, treatment of wastewater containing alkene, alcohol, and benzene [13-14]. The principle of Fenton reagent is the decomposition of oxidant to form hydroxyl radical, which can oxidize organic pollutants. Hu et al. [15] found that Fenton reagent can degrade BPA in a high rate when the reaction pH was kept at 3.94. Iordache et al. [16] also investigated the degradation of BPA by Fenton reagent, and the results showed that B PA can be al mostly completely degraded after one hour reaction when the initial mass concentration of BPA was $25 \mathrm{mg} / \mathrm{L}$. Although it has been proved that Fenton reagent can degrade BPA, there are still some deficiencies, such as the removal of BPA needs a good effect when the $\mathrm{pH}$ is about 3 . On the other hand, $\cdot \mathrm{OH}$ would be quenched quickly once it is generated, resulted to a rather high consumption of $\mathrm{H}_{2} \mathrm{O}_{2}$. Compared with other oxidation technologies, Fenton has the characteristics of fast, efficient, mild reaction conditions and strong oxidation; $\mathrm{H}_{2} \mathrm{O}_{2}$ eventually converted into water. In addition, Fenton also has advantages of simple equipment, low energy consumption and operating cost.

This paper is to study the degradation of BPA by Fenton reagent under different reaction conditions, and the experimental results are analyzed to determine the optimal parameters and operation condition parameters, and also to unveil its degradation path.

\section{Materials and Methods}

\subsection{Reagents and materials}

The chemical reagents were not all analytically. Bisphenol $A$ (BPA GR), potassium bisulfate $\left(\mathrm{KHSO}_{5} ¥ 0.5 \mathrm{KHSO}_{4} 0.5 \mathrm{~K}_{2} \mathrm{SO}_{4} \mathrm{AR}\right)$, cobalt nitrate hexahydrate $\left(\mathrm{Co}\left(\mathrm{NO}_{3}\right)_{2} ¥ 6 \mathrm{H}_{2} \mathrm{O}\right.$ $A R$ ) were obtained from Aladdin Reagent $\mathrm{Co}$., Ltd. Sodium hydroxide ( $\mathrm{NaOH} A R$ ), Ferrous sulfate heptahydrate, $\left(\mathrm{FeSO}_{4} ¥ 7 \mathrm{H}_{2} \mathrm{OAR}\right)$, hydrogen peroxide $\left(30 \% \mathrm{H}_{2} \mathrm{O}_{2} \mathrm{AR}\right)$ were obtained from Tianjin Damao chemical reagent plant. Sodium chloride ( $\mathrm{NaCl} A R)$ was purchased from Tianjin Baishi Chemical $\mathrm{Co}$., Ltd. Sulfuric acid $\left(\mathrm{H}_{2} \mathrm{SO}_{4} \mathrm{AR}\right)$ and sodium sulfite $\left(\mathrm{Na}_{2} \mathrm{SO}_{3}\right)$ were purchased from Guoyao Chemical Reagent Co., Ltd. Methanol $\left(\mathrm{CH}_{3} \mathrm{OH} \mathrm{HP}\right)$ and dichloromethane $\left(\mathrm{CH}_{2} \mathrm{Cl}_{2} \mathrm{HP}\right)$ were purchased from Duksan company in Germany, respectively. All experiments were carried out using double distilled water.

\subsection{Instruments and equipment used in the experiment}

In the experiment, Centrifuge 5418 model from Eppendenf was used to separate solid and liquid. Use WA TERS A cquity HClass UPLC to detect the concerntration of BPA. GCMS model is 7890a-5975c, A gilent. Other instruments includes, Qingdao Haike DCY -12S 
nitrogen blowing concentrator, Shanghai Meixiang CJJ-6 magnetic heating agitator, and Shanghai Leici PHS-3C pH meter.

\subsection{Analytical methods}

\subsubsection{BPA detection indicators}

UPLC was used to detect the concentration of BPA. The degradation rate of BPA was taken as an indicator. The pretreatment of the experiment was divided into two steps. In the water distribution part, if the concentration of BPA in water samples was below $1 \mathrm{mg} / \mathrm{L}, 1.5$ $\mathrm{mL}$ of the samples were placed in the colorimetric tube, and were mixed with $3.5 \mathrm{~mL}$ of the chromatographic pure methanol solution, and then poured into the sample bottles for testing. For the actual wastewater, more than $2 \mathrm{~mL}$ of the static B PA sample was centrifuged at a speed of $12000 \mathrm{r} / \mathrm{min}$ for $5 \mathrm{~min}$. Afterwards, $1.5 \mathrm{~mL}$ supernatant was placed in a colorimetric tube, and was mixed with $3.5 \mathrm{~mL}$ of the chromatographic pure methanol solution, and then poured into the sample bottles for testing.

\subsubsection{Detection of oxidation intermediates}

GC-MS was used to detect the intermediates in the reaction process. A bout $50 \mathrm{~mL}$ water sample after pretreatment was taken, and was adjusted its $\mathrm{pH}$ to 2.0 using hydrochloric acid. $M$ ore than $1 \mathrm{~g}$ sodium chloride and $5 \mathrm{~mL}$ dichloromethane were added to oscillate extraction for $10 \mathrm{~min}$. A fter stratified statically, the sample was dehydrated with anhydrous sodium sulfate and transferred to the colorimetric tube. The extraction was repeated twice, the extracting liqiud was mixed. A nitrogen concentrator was used to concentrate at $25{ }^{\circ} \mathrm{C}$. A fter the liquid was dried, $1 \mathrm{~mL} \mathrm{n}$-hexane was added, shook appropriately, and poured into the sample to be tested.

\section{Results and discussion}

\subsection{Effect of initial BPA concentration and reaction time}

During the degradation of BPA by Fenton reagent, the main factors influencing the degradation of $\mathrm{BPA}$ were $\mathrm{C}\left(\mathrm{H}_{2} \mathrm{O}_{2}\right) / \mathrm{C}\left(\mathrm{Fe}^{2+}\right)$, $\mathrm{pH}$ and temperature. The importance ranking is $\mathrm{C}\left(\mathrm{H}_{2} \mathrm{O}_{2}\right) / \mathrm{C}\left(\mathrm{Fe}^{2+}\right)>\mathrm{pH}>$ temperature[15] [17]. Through the following single-factor experiments, the factors were investigated and the optimal conditions were determined. During the experiment, the initial concentration of BPA was $1000 \mu \mathrm{g} / \mathrm{L}$, the concentration of $\mathrm{Fe}^{2+}$ was $8 \mu \mathrm{mol} / \mathrm{L}$, and the concentration of $\mathrm{H}_{2} \mathrm{O}_{2}$ was $80 \mu \mathrm{mol} / \mathrm{L}$. The initial $\mathrm{pH}$ value of the solution was 3.5 , the temperature was $25 \pm 1{ }^{\circ} \mathrm{C}$, and the oxidation reaction time was $30 \mathrm{~min}$.

As shown in Figure $1 \mathrm{a}$ ) and b), using $\mathrm{H}_{2} \mathrm{O}_{2}$ only had a poor ability to remove BPA, but when $\mathrm{Fe}^{2+}$ and $\mathrm{H}_{2} \mathrm{O}_{2}$ were added together, the degradation rate of $\mathrm{BPA}$ was significantly increased. The degradation rate of $B P A$ also increased with the increase of $\mathrm{Fe}^{2+}$ and $\mathrm{H}_{2} \mathrm{O}_{2}$ concentration. However, with the further increase of $\mathrm{Fe}^{2+}$ concentration, the degradation rate of BPA decreased. When the concentration of $\mathrm{H}_{2} \mathrm{O}_{2}$ was increased to $1000 \mu \mathrm{mol} / \mathrm{L}$, the removal effect of BPA degradation rate did not increase significantly with the increase of $\mathrm{H}_{2} \mathrm{O}_{2}$ concentration.

This is because $\mathrm{H}_{2} \mathrm{O}_{2}$ can hardly form hydroxyl radicals $(\cdot \mathrm{OH})$ without $\mathrm{Fe}^{2+}$, and the addition of $\mathrm{Fe}^{2+}$ can trigger a chain reaction to produce $\cdot \mathrm{OH}$. W ith the increase of the initial 
concentrations of $\mathrm{Fe}^{2+}, \mathrm{H}_{2} \mathrm{O}_{2}$ and $\mathrm{BPA}$, the generation of $\bullet \mathrm{OH}$ yields, the degradation effect of organic compounds increases, and the removal amount of BPA increases. However, for a certain amount of reactive substances, due to the limited generation rate of $\bullet \mathrm{OH}$, when the concentration of reactive substances increases to a certain extent, even further increasing the concentration would not improve the removal effect of BPA, the removal ability of BPA decreases.

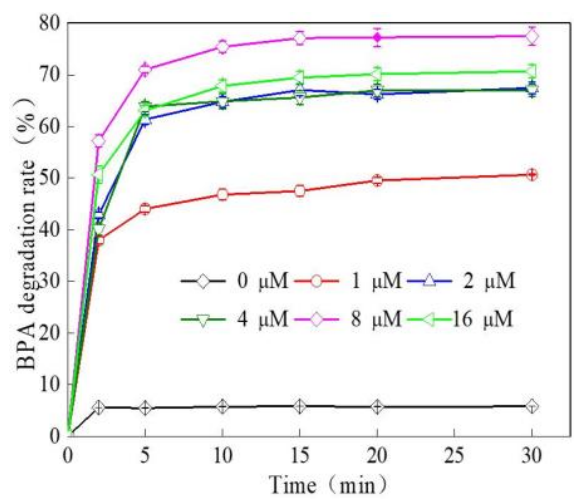

a)

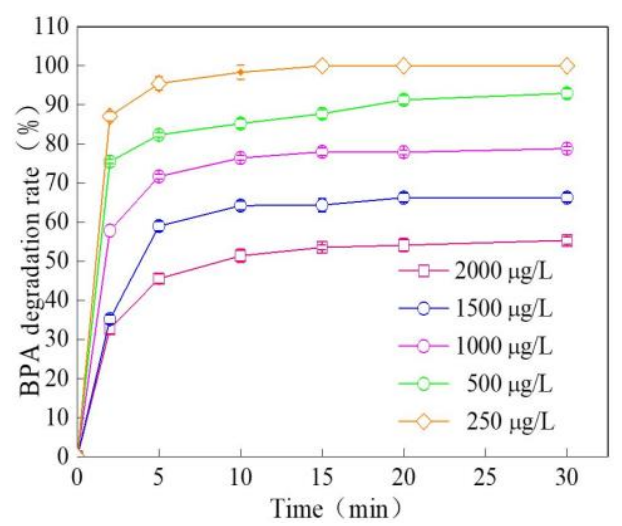

c)

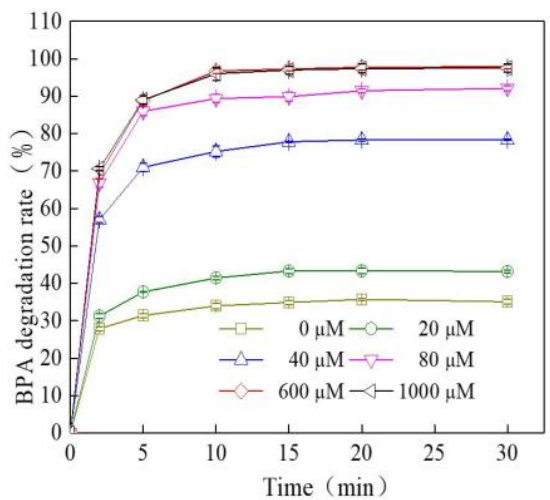

b)

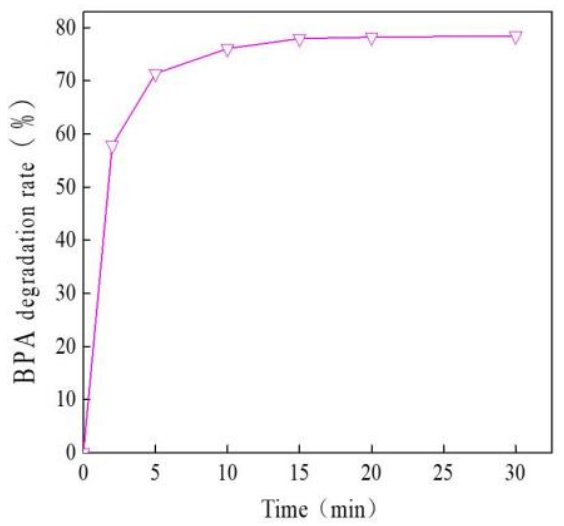

d)

Fig. 1. Effect of different reagent concentration and reaction time in Fenton process: (a) $\mathrm{Fe}^{2+}$ concentration, (b) $\mathrm{H}_{2} \mathrm{O}_{2}$ concentration, (c) BPA initial concentration, (d) reaction time

As shown in Figure $1 \mathrm{c}$ ), al ong with the increase of initial concentration of BPA, it had a relatively increased of removal amount and the reduce of removal rate of BPA. This is because with the increase of initial concentration of BPA, the number of molecules per unit volume BPA also had a increase. In the case of the Fenton reagent concentration was constant, increasing the chance of a collision between them can remove more BPA. but for a certain amount of $\mathrm{H}_{2} \mathrm{O}_{2}$, the production rate of $\bullet \mathrm{OH}$ was limited, thus $\mathrm{BPA}$ removal ability was limited, so the removal rate of BPA decreased along with the increased of initial concentration of BPA. As shown in Figure $1 \mathrm{~d}$ ), A fter a 15 min reaction, the degradation rate of BPA was $77.95 \%$, which had achieve basically stable. Even if the reaction time increased, BPA removal efficiency was not significantly increased. So there have a advise that similar experiments to control the reaction time of $15 \mathrm{~min}$. 
The optimal dosage ratio of $\mathrm{C}\left(\mathrm{H}_{2} \mathrm{O}_{2}\right) / \mathrm{C}\left(\mathrm{Fe}^{2+}\right)$ is approximately 10 , at which has the best degradation effect of BPA. Therefore, during the following study, the concentration of $\mathrm{H}_{2} \mathrm{O}_{2}$ was set as $80 \mu \mathrm{mol} / \mathrm{L}$, the concentration of $\mathrm{Fe}^{2+}$ as $8 \mu \mathrm{mol} / \mathrm{L}$ in the BPA experiment. The reaction time could be kept as low as $15 \mathrm{~min}$.

\subsection{Optimization of operation conditions}

In order to study the effect of $\mathrm{pH}$ and temperature, the initial concentration of BPA was controlled at $1000 \mu \mathrm{g} / \mathrm{L}$, the concentration of $\mathrm{H}_{2} \mathrm{O}_{2}$ was controlled at $80 \mu \mathrm{mol} / \mathrm{L}$, and the concentration of $\mathrm{Fe}^{2+}$ was controlled at $8 \mu \mathrm{mol} / \mathrm{L}$.

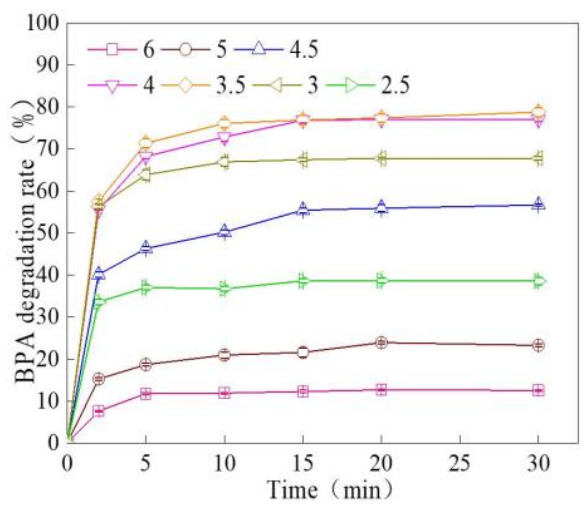

a)

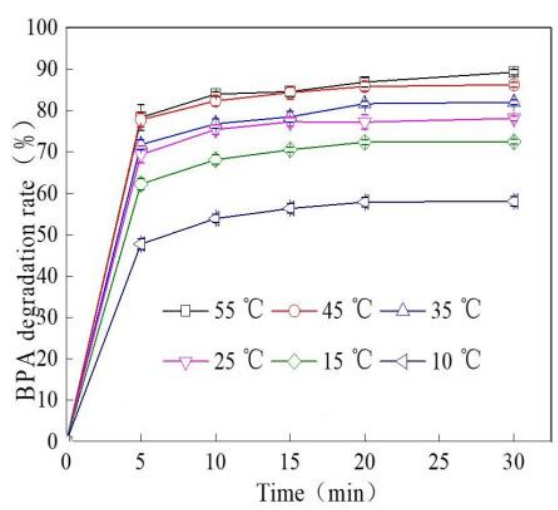

b)

Fig. 2. Effect of different concentration and reaction time in Fenton process: (a) solution initial pH, (b) reaction temperature

As shown in figure 2 , the results showed that the $\mathrm{pH}$ value had a great influence on the degradation of BPA. When the $\mathrm{pH}$ was between 3 and 4 , Fenton method had a good degradation effect on BPA. Higher or lower $\mathrm{pH}$ would reduce the degradation effect of Fenton $\$$ reagent. The classic Fenton process theory believes that higher $\mathrm{pH}$ leads to $\mathrm{Fe}^{2+}$ being oxidized to iron hydroxide complex, and lower $\mathrm{pH}$ prevents $\mathrm{Fe}^{3+}$ from being reduced to $\mathrm{Fe}^{2+}$. Temperature can affect the rate of chemical reaction as well. As the temperature increases, the removal effect of BPA increases. Appropriate temperature increases the reactivity, but excessive temperature leads to $\mathrm{H}_{2} \mathrm{O}_{2}$ breaking down into $\mathrm{H}_{2} \mathrm{O}$ and $\mathrm{O}_{2}$, weakening the treatment effect of BPA.

\subsection{Degradation mechanism of BPA by Fenton oxidation}

In this section, GC-MS method was used to qualitatively analyze the BPA products treated by Fenton $@$ reagent. Based on previous study, the possible degradation path of BPA by Fenton process would be inferred [18-19]. The relevant experimental conditions were as follows, the initial concentration of BPA was $1000 \mu \mathrm{g} / \mathrm{L}$, the concentration of $\mathrm{H}_{2} \mathrm{O}_{2}$ was $80 \mu \mathrm{mol} / \mathrm{L}$, the concentration of $\mathrm{Fe}^{2+}$ was $8 \mu \mathrm{mol} / \mathrm{L}$, the initial $\mathrm{pH}$ of the solution was 3.5 , the temperature was $25 \pm 1{ }^{\circ} \mathrm{C}$, and the reaction time was $30 \mathrm{~s}, 1 \mathrm{~min}, 3 \mathrm{~min}, 5 \mathrm{~min}$ and 10 min respectively.

\subsubsection{Intermediate product}

The intermediate products are shown in table 1 below. 
Table 1. Intermediates during BPA degradation by Fenton method

\begin{tabular}{|c|c|c|c|c|c|c|}
\hline NO. & $\begin{array}{l}\text { Retention } \\
\text { time } \\
\text { (min) }\end{array}$ & Name & $\begin{array}{l}\text { M olecular } \\
\text { formula }\end{array}$ & $\begin{array}{l}\text { Molecular } \\
\text { weight }\end{array}$ & $\begin{array}{l}\text { Molecular structure } \\
\text { formula }\end{array}$ & $\begin{array}{l}\text { Detection ion } \\
(\mathrm{m} / \mathrm{z})\end{array}$ \\
\hline
\end{tabular}

1

5.99

Phenol

$\mathrm{C}_{6} \mathrm{H}_{6} \mathrm{O}$

94

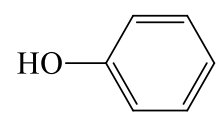

$94(86)$

66(47)

$2 \quad 6.35$ 1,4-B enzoquinone $\quad \mathrm{C}_{6} \mathrm{H}_{4} \mathrm{O}_{2} \quad 108$<smiles>O=C1C=CC(=O)C=C1</smiles>

$108(100)$

$82(61)$

$54(86)$

$55(55)$

$110(41)$

99(56)

3

6.85

Hydroquinone

$\mathrm{C}_{6} \mathrm{H}_{6} \mathrm{O}_{2}$

110

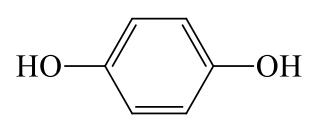

$65(48)$

$55(100)$

$4 \quad 9.13 \quad$ M aleic acid $\quad \mathrm{C}_{4} \mathrm{H}_{4} \mathrm{O}_{4} \quad 116$<smiles>O=C(O)/C=C\C(=O)O</smiles>

99(39)

$72(32)$

$68(44)$

$55(100)$

$4-$

$5 \quad 12.86 \quad$ Isopropenylpheno $\mathrm{C}_{9} \mathrm{H}_{10} \mathrm{O}$

134

$134(100)$

$119(83)$

91(52)

78(19)

136(22)

$121(35)$

103(100)

91(100)

4-

$7 \quad 16.60$ Hydroxyacetophe $\mathrm{C}_{8} \mathrm{H}_{8} \mathrm{O}_{2}$

136

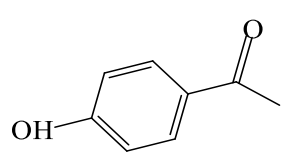

136(29)

93(40)

121(100)

65(40) 


$8 \quad 21.70$ Bisphenol $\mathrm{A} \quad \mathrm{C}_{15} \mathrm{H}_{16} \mathrm{O}_{2} \quad 228$

\subsubsection{Fenton degradation pathway of BPA}

According to the previous study, the degradation path of BPA in solution was speculated, as shown in Fig 3. Fenton process is essentially a process in which $\mathrm{H}_{2} \mathrm{O}_{2}$ is catalyzed by $\mathrm{Fe}^{2+}$ to produce hydroxyl radicals $(\bullet \mathrm{OH})$ with strong oxidization, high electronegative or electrophilic (electron affinity is $569.3 \mathrm{~kJ}$ ) that degrade BPA. $\bullet \mathrm{OH}$ reacts with BPA molecules, gradually oxidizing them into small molecules of organic matter until they are thoroughly mineralized into $\mathrm{CO}_{2}$ and $\mathrm{H}_{2} \mathrm{O}$.
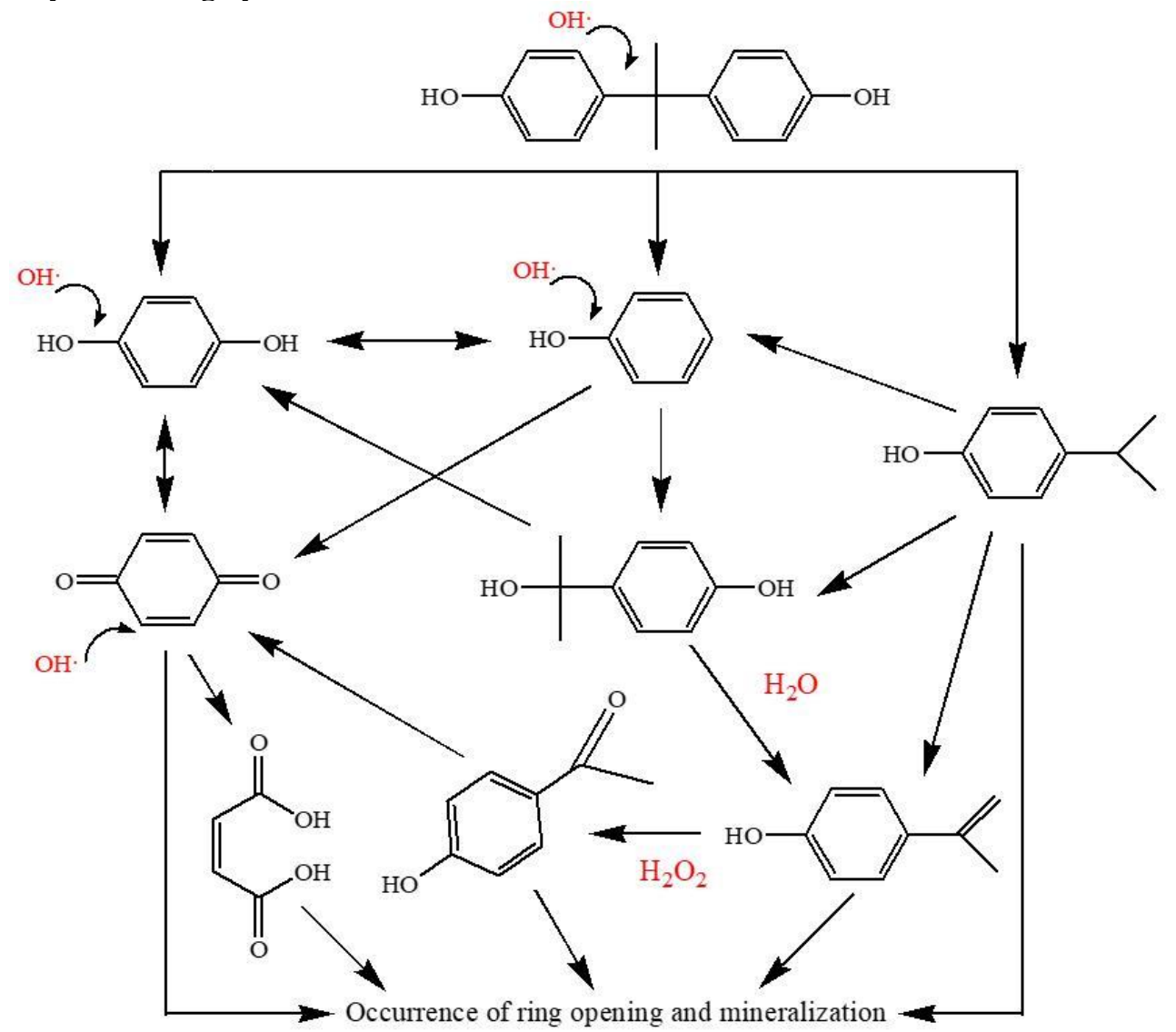

Fig. 3. Degradation path of bisphenol A in water by Fenton method

When BPA in water is oxidized by Fenton method, hydroxyl radicals attack the connection between benzene ring and isopropyl of BPA, breaking it off and forming intermediate products such as $p$-diphenol, phenol and isopropyl phenol. Under the action of hydrogen peroxide and hydroxyl free radical, the phenol hydroxyl groups in counterpoint is more active, easily oxidized into the two ketone benzene, hydroquinone can also be further oxidation of phenol and benzoquinone, benzoquinone ring fractures, further generates maleic acid, and finally will be mineralized to $\mathrm{CO}_{2}$ and $\mathrm{H}_{2} \mathrm{O}$. Additionally, isopropyl 
phenol can be oxidized to 4-(1-hydroxy-1-methyl-ethyl)-phenol (HMEP), then HMEP is further dehydrated to produce p-isopropyl phenol. P-isopropyl phenol generates hydroxy acetophenone under the oxidation of $\mathrm{H}_{2} \mathrm{O}_{2}$, hydroxy acetophenone is further oxidized into maleic acid. Finally, it is thoroughly mineralized.

\section{Conclusion}

In this paper, the degradation of BPA by Fenton oxidation was studied. Single factor experiments were used to find out the optimal experimental conditions. The degradation mechanism and pathway of BPA under Fenton oxidation were further analyzed. When the ratio of $\mathrm{C}\left(\mathrm{H}_{2} \mathrm{O}_{2}\right) / \mathrm{C}\left(\mathrm{Fe}^{2+}\right)$ is 10 (mole ratio) and the initial $\mathrm{pH}$ is $3.5 \sim 4.5$, Fenton method has a good degradation effect on BPA. The degradation effect of BPA increases with the increase of temperature. When the concentration of the BPA is $1 \mathrm{mg} / \mathrm{L}$, the optimal conditions are as follows, the initial $\mathrm{pH}$ is 3.5 , the concentration of $\mathrm{H}_{2} \mathrm{O}_{2}$ is $80 \mu \mathrm{mol} / \mathrm{L}$, and the concentration of $\mathrm{Fe}^{2+}$ is $8 \mu \mathrm{mol} / \mathrm{L}$. After $15 \mathrm{~min}$ reaction at $25 \pm 1{ }^{\circ} \mathrm{C}$, the degradation rate of $\mathrm{BPA}$ is $77.95 \%$. GC-MS was used to detect the intermediate products in Fenton process. It was found that the degradation of BPA by Fenton method could destroy the molecular structure of BPA, break the chemical bond between benzene ring and isopropyl, and then produce the intermediate products such as p-diphenol, phenol and isopropyl phenol. Under the further action of hydroxyl radical, the final ring opening mineralization was $\mathrm{CO}_{2}$ and $\mathrm{H}_{2} \mathrm{O}$.

\section{Acknowledgement}

This research was supported by the Shenzhen Science and Technology Funding Project [grant number JSGG20170414101900541, and JCYJ20170816102318538]; the National Natural Science Foundation of China [grant numbers 51678183, 51408149]; and the Project supported by Guangdong Natural Science Foundation [grant number 2017A030313285].

\section{References}

[1] Y. Zhu, W.Q. Shu, J.B. Zhuo, et al. Preliminary study on the in vitro estrogenic activity of bisphenol $A$ and its mechanism [J]. Chongqing Environmental Science, 25, 2022(2003).

[2] G. P. A nipsitakis, D. D. Dionysiou. Degradation of Organic Contaminants in Water with Sulfate Radicals Generated by the Conjunction of Peroxymonosulfate with Cobalt [J]. Environmental Science \& Technology, 37, 4790-4797(2003).

[3] M. S. Rordriguez, M. L. A Ida, D. Barcelo. A nalysis of Bisphenol A in Natural W ater by M eans of A n Optical Immunosensor [J]. W at Res, 39, 5071-5079(2005).

[4] H.F. Zhang, J.Y. Hu, H. Chang, et al. SPE-LC-M S determination of bisphenol A in drinking water sources and tap water in Hangzhou [J]. Environmental chemistry, 23, 584586(2004).

[5] J.W. Tang, Y.B. Zhou, Y.X. Xu, et al. Study on the removal of bisphenol A from water by modified sulfonated peat [J]. Environmental pollution and control; 33, 2934(2011).

[6] S.C. Huang, Y.P. Hang. Simultaneous determination of bisphenol A and tetrabromobisphenol A in plastic products by liquid chromatography-mass spectrometry [J]. Chromatography, 28, 863-866(2010).

[7] Y.C. Wang, Q.K. Liu, Q.X. Zhao. Adsorption characteristics of activated carbon for 
bisphenol A [J]. Journal of East China University of science and technology: Natural Science Edition, 32, 431-433(2006).

[8] S.J. Chen, X.R. Chen, L. Y an, et al. Study on the interaction characteristics of toxic organic compounds BPA and Chlorella vulgaris [J]. Environmental science, 4, 040(2014).

[9] X. Tang, L.M. Zhou, L. Lu, et al. Ozonation of bisphenol A in water by activated carbon supported $\mathrm{Fe}^{3+}[\mathrm{J}]$. Liaoning chemical, 6, 002(2014).

[10] Jun. Jiang, X.Y. Li. Research progress in degradation of bisphenol A, an environmental endocrine disruptor [J]. Shanghai chemical industry, 34, 25-30(2009).

[11] K.J. Zhang. Study on the treatment of acid rose red B dyeing wastewater by Fenton reagent [D]. Tianjin: M aster@ thesis of Tianjin University, 21-25(2004).

[12] E. Neyens, J. Baeyens. A Review of Classic Fenton's Peroxidation as an Advanced Oxidation Technique [J]. J ournal of Hazardous M aterials, 98, 33-50(2003).

[13] H. Zhang, C.P. Huang, et al. A nalysis of the factors affecting the treatment of landfill leachate by Fenton reagent [J]. China water supply and drainage, 18, 14-17(2002).

[14] Y.M. Wang, X. Zhao, L.N. Xu, et al. Study on treatment of oilfield oil production wastewater by Fenton oxidation and biochemical combination technology [J]. Environmental pollution treatment technology and equipment, 5, 74-78(2004).

[15] L. Hu, N.Y. Gao. Study on degradation of endocrine disruptor bisphenol A by Fenton reagent [J]. China water supply and drainage, 27, 80-82, 86(2011).

[16] I. Ioan, S. Wilson, E. Lundanes, et al. Comparison of Fenton and Sono-Fenton Bisphenol A Degradation [J]. J ournal of Hazardous M aterials, 142, 559-563(2007).

[17] H. Katsumata, S. Kawabe, S. K aneco, et al. Degradation of B isphenol A in W ater by the Photo-Fenton [J]. Journal of Photochemistry and Photobiology A: Chenistry, 162, 297-305(2004).

[18] P. J. Chen, S. W. Kullman, D. E. Hinton, et al. Comparisons of Polychromatic and Monochromatic UV-Based Treatments of Bisphenol A in Water Via Toxicity A ssessments[] ]. Chemosphere, 68, 1041-1049(2007).

[19] S. Fukahori, H. Ichiura, T. Kitaoka, et al. Capturing of Bisphenol A Photodecomposition Intermediates by Composite Ti02-Zeolite Sheets[] ]. A pplied Catalysis B : Environmental, 46, 453-462(2003). 